\title{
The effect of gelatin amount on the properties of PLA/TPS/gelatin extruded sheets
}

\author{
Ana Paula de Oliveira Pizzoli', Fabio Yamashita², Odinei Hess Gonçalves', Marianne Ayumi Shirai' and \\ Fernanda Vitória Leimann ${ }^{1 *}$
}

\author{
'Programa de Pós-graduação em Tecnologia de Alimentos, Universidade Tecnológica Federal do \\ Paraná - UTFPR, Campo Mourão, PR, Brazil \\ 2Departamento de Ciência e Tecnologia de Alimentos, Centro de Ciências Agrárias, \\ Universidade Estadual de Londrina - UEL, Londrina, PR, Brazil \\ *fernandaleimann@utfpr.edu.br
}

\begin{abstract}
Films and sheets composed by poly (lactic acid) (PLA)/thermoplastic starch (TPS) and TPS/gelatin blends have already been produced and characterized in the literature. However, materials produced with these three biopolymers have not been clearly investigated. In this work, extruded sheets were produced with PLA, TPS (glycerol as plasticizer) and different amounts of gelatin $(0,1,3$ and $5 \mathrm{wt} \%)$ in a pilot scale co-rotating twin-screw extruder coupled with a calender. The extruded sheets were characterized in regards to their water solubility, thickness, density, water vapor permeability (WVP), moisture sorption isotherms, mechanical properties and microstructure. The results showed an increase in solubility and WVP besides a decrease of about 30\% in tensile strength, Young's modulus and elongation at break. Extruded sheets microstructure revealed smother surfaces and homogeneous morphology with the addition of gelatin. The experiments demonstrated that extrusion and calendering process is a viable way to produce PLA/TPS/gelatin sheets with interesting properties.
\end{abstract}

Keywords: biodegradable polymers, extrusion-calendering, hydrophilicity, mechanical characterization, microstructure.

\section{Introduction}

Sustainable development policies tend to expand with the decreasing reserve of fossil fuel and the growing concern for the environment, consequently, biodegradable polymers have emerged as potential alternatives for petrochemical plastics ${ }^{[1]}$. Poly(lactic acid) (PLA) is becoming a popular biodegradable engineering plastic due to its mechanical properties and easy processability ${ }^{[2]}$. PLA is a versatile material with applications in the medical, textile, and packaging fields, but its brittleness and high cost in comparison to petroleum-based thermoplastics have limited its applications ${ }^{[3]}$. Polymer blends based on thermoplastic starch (TPS) have been used to lower the costs of other materials ${ }^{[4]}$ and like starch, other polysaccharides, i.e. cellulose, chitin, chitosan and proteins i.e. gelatin, casein, pectin, etc. have found innumerable applications in biodegradable products ${ }^{[5]}$. Starch is a main storage energy source for higher plants and one of the primary sources of calories in human nutrition. Native starch occurs as water-insoluble granules whose sizes and shapes are dependent on its botanical source ${ }^{[4,6]}$. Starch granules can be gelatinized in the presence of a plasticizer and heat, during which the crystalline structure is disrupted (thermoplastic starch, TPS). This allows the starch to flow at high temperatures so it can be processed using conventional polymer processing equipment ${ }^{[7,8]}$. Gelatin is another low-cost and abundant raw material, and is well-known for its good film forming properties ${ }^{[9,10]}$.

Many studies have been made on the combination of starch and gelatin ${ }^{[9-13]}$ and also of starch and PLA ${ }^{[14,15]}$. However, the literature is lacking sufficient studies on the combination of these three biopolymers and how they could eventually interact to form the final microstructure. For instance, a PLA-starch- gelatin blend (also containing calcium carbonate and glycerol) obtained by thermo pressing was proposed ${ }^{[16]}$. The resulting material showed to be easily degradable in a marine environment, which is highly desirable for most forms of applications. However, the authors focused mainly on the biodegradation behavior and on its amorphous/crystalline microstructure characterization under optical polarization microscopy. A more thorough evaluation should be performed to determine how blend composition could affect the mechanical and barrier properties of the material because they would give an insight on the material applicability and performance.

In this context, the present study develops a novel biodegradable packaging blend based on PLA/TPS/gelatin. The influence of gelatin content on the mechanical properties, microstructure, water vapor barrier properties, humidity, density and thickness was investigated.

\section{Materials and Methods}

\subsection{Materials}

PLA Ingeo 4043D (Natureworks LLC, Cargill, USA), cassava starch (Indemil, Brazil), glycerol (Dinâmica, Brazil), as plasticizing for the starch, and gelatin (Dinâmica, P.A., Brazil) were used to produce the extruded blend sheets. Magnesium nitrate and calcium chloride (Vetec, Brazil) were used to control the relative humidity during sheets conditioning. 


\subsection{Production of pellets and sheets}

The procedure adopted for the production of pellets and sheets was described by Shirai et al. ${ }^{[17]}$ with some modifications, and the sheets formulations are presented in Table 1. A control formulation (FC) was produced with 50:50 PLA:TPS with no added gelatin. In FG1, FG3 and FG5 formulations, gelatin percentage (wt $\%$ ) is related to TPS mass (starch and glycerol). The proportion between starch and glycerol was kept constant in all formulations (33 g glycerol/100 g starch).

Initially, gelatin was allowed to gelatinize in contact with glycerol during 24 hours at room temperature. After that, starch and PLA were added, manually mixed and extruded as cylindrical profiles in a single-screw extruder (BGM, EL-25 model, Brazil) using the following processing conditions: screw diameter of $25 \mathrm{~mm}$, screw length of $28 \mathrm{D}$, screw speed of $30 \mathrm{rpm}$, and temperature profile of $90 / 180 / 180 / 180^{\circ} \mathrm{C}$ at the four heating zones. The extruded cylindrical profiles were cooled at room temperature and, then, pelletized.

The obtained pellets were extruded in a pilot co-rotating twin-screw extruder (BGM, D-20 model) coupled with a calender (AX-Plásticos, Brazil) for sheet production. The processing conditions employed were: screws diameter (D) of $20 \mathrm{~mm}$, screws length of $35 \mathrm{D}$, temperature profile of $100 / 170 / 170 / 170 / 175^{\circ} \mathrm{C}$, screw speed of $100 \mathrm{rpm}$, and feed speed of $30 \mathrm{rpm}$. The distance between the calender rolls was kept at $0.8 \mathrm{~mm}$ and the rolls' speed was adjusted depending on the formulation to maintain continuous processing.

\subsection{Thickness, density and moisture content}

Sheet thickness was determined with the use of a digital micrometer (Starrett, Brazil) with $0.001 \mathrm{~mm}$ resolution. Ten random points were used from each sample. Two density determination samples $(20 \times 20 \mathrm{~mm})$ were kept in a desiccator containing anhydrous calcium chloride ( $0 \%$ relative humidity) for two weeks and finally weighted ${ }^{[18]}$. Two moisture content determination sheets samples were weighted $\left(\mathrm{mi}_{1}\right)$ and conditioned in a forced air oven by $24 \mathrm{~h}$ at $70^{\circ} \mathrm{C}$. After that, the sheets were weighted again $\left(\mathrm{ms}_{1}\right)$ and the humidity $(\%)$ was calculated with the Equation 1.

$U=\frac{\left(m i_{1}-m s_{1}\right)}{m i_{1}} .100$

\subsection{Water solubility}

Water solubility was defined as the dry mass content from the sheets that was solubilized after $24 \mathrm{~h}$ of immersion in water at $25^{\circ} \mathrm{C}$. The procedure adopted was described by

Table 1. Composition of the PLA/TPS/gelatin extruded sheets FC (control sample), FG1 (0.5\%gelatin), FG3 (1.5\% gelatin) and FG5 (2.5\% gelatin).

\begin{tabular}{ccccc}
\hline Formulation & $\begin{array}{c}\text { PLA } \\
(\%)\end{array}$ & $\begin{array}{c}\text { Starch } \\
(\%)\end{array}$ & $\begin{array}{c}\text { Glycerol } \\
(\%)\end{array}$ & $\begin{array}{c}\text { Gelatin } \\
(\%)\end{array}$ \\
\hline FC & 50.0 & 37.5 & 12.5 & 0 \\
FG1 & 50.0 & 37.1 & 12.4 & 0.5 \\
FG3 & 50.0 & 36.4 & 12.1 & 1.5 \\
FG5 & 50.0 & 35.6 & 11.9 & 2.5 \\
\hline
\end{tabular}

Soares et al. ${ }^{[14]}$. Sheet samples $(2 \times 2 \mathrm{~cm})$ were weighted $\left(\mathrm{mi}_{2}\right)$ and then immersed in water $\left(200 \mathrm{~mL}, 25+/-2{ }^{\circ} \mathrm{C}\right)$ by $24 \mathrm{~h}$. After that, the residual sheet was removed and dried at $70{ }^{\circ} \mathrm{C}$ in a forced air oven for $24 \mathrm{~h}$. Finally the sheet was then weighed $\left(\mathrm{ms}_{2}\right)$ and water solubility $(\%)$ was calculated with Equation 2; ma is the mass of water calculated from the humidity, and $\left(\mathrm{mi}_{2}-\mathrm{m}_{\mathrm{a}}\right)$ the initial mass of the sheet on a dry basis.

$$
S O L=\frac{\left(\left(m i_{2}-m_{a}\right)-m s_{2}\right)}{\left(m i_{2}-m_{a}\right)} .100
$$

\subsection{Water Vapor Permeability (WVP)}

The water vapor permeability of the sheets was determined in appropriate diffusion cells, using a relative humidity $(\mathrm{RH})$ of $2 \%$ inside the cell and $75 \%$ outside the cell ${ }^{[19]}$. All tests were performed in triplicate.

\subsection{Moisture sorption isotherm}

The moisture sorption isotherms of the sheets were obtained by static gravimetric method using saturated saline solutions $(11.8 \%, 32.8 \%, 52.9 \%, 75 \%$ and $87 \%)$ to promote different relative humidity values. The sheets were previously dried in desiccator containing anhydrous calcium chloride ( $0 \%$ relative humidity) for two weeks, and then maintained in closed recipients with different saturated saline solution at $25^{\circ} \mathrm{C}$. The samples were weighed in regular intervals until three equal weight measurements were obtained (equilibrium condition). The absolute humidity (dry base) was determined by the oven method $\left(105^{\circ} \mathrm{C}\right.$ for $24 \mathrm{~h}$ ). The GAB (Guggenheim-Anderson-de Boer) model (Equation 3) was used to fit the experimental data. In this equation, the parameter "Xw" is the equilibrium moisture content (g water/g dry solid) at a known water activity $\left(\mathrm{a}_{\mathrm{w}}\right)$, mo is the monolayer water content, " $\mathrm{C}$ " is the Guggenheim constant (representing the sorption heat of the first layer), and " $\mathrm{K}$ " is the sorption heat of the multilayer. The parameters of the GAB model were determined using non-linear regression performed with the Statistica 7.0 software. The test was perfomed in triplicate.

$$
X w=\frac{m_{0} \cdot C \cdot K \cdot a_{w}}{\left(1-K \cdot a_{w}\right) \cdot\left(1-K \cdot a_{w}+C \cdot K \cdot a_{w}\right)}
$$

\subsection{Mechanical properties}

The tensile strength tests were performed with a texture analyser (Stable Micro Systems, TA XTplus model, England) based on the American Society for Testing and Material standards ASTM D- $882-00^{[20]}$. The samples were previously conditioned at $23 \pm 2{ }^{\circ} \mathrm{C}$ and $53 \pm 2 \%$ of relative humidity for $48 \mathrm{~h}$. The properties evaluated were tensile strength (MPa), elongation at break (\%), and Young's modulus (MPa). Ten samples were tested for each formulation.

\subsection{Scanning electron microscopy (SEM)}

The microstructure of the surface and fractured sheets was analyzed with a scanning electron microscope (Philips, XL-30 model, Holland) with electron source of tungsten 
and detectors of secondary and backscattered electrons at $20 \mathrm{kV}$. The sheet samples were immersed in liquid nitrogen and then fractured. After that, they were coated in gold using a sputter coater (BALTEC, SCD 005 model, Switzerland).

\subsection{Statistical analysis}

The results were evaluated using analysis of variance (ANOVA), and treatment means were compared using Tukey's test at the $5 \%$ significance level $(\mathrm{p}<0.05)$ with Statistica 7.0 software (Stat-Soft, Tulsa, OK, USA).

\section{Results and Discussions}

PLA/TPS/gelatin extruded sheets presented good processability and were successfully obtained. The results obtained for the formulations, taking into account the effect of the gelatin amount, are presented as follows.

\subsection{Sheets appearance, thickness and density}

It was possible to observe visually, as shown at Figure 1, that the increase in the amount of gelatin (FG3 and FG5) resulted in a more yellowish appearance than formulation FG1, which was white. All sheets presented opaque appearance. Similar results were also observed by Fakhouri et al. ${ }^{[10,12]}$. Extruded TPS based materials are opaque and whitish due to the alignment of the chains and subsequent crystallization induced by extrusion which do not occurs in films produced by casting technique ${ }^{[10]}$.

Thickness and density values obtained for PLA/TPS and PLA/TPS/gelatin sheets are presented in Table 2. No significant difference was detected $(p>0.05)$ between formulations with distinct gelatin amounts. Choi et al. ${ }^{[21]}$ observed an increase in density of an artificial skin (composed by sodium alginate and gelatin) as gelatin amount was increased. The authors used gelatin amounts between 50 and $90 \%$ from the polymeric content which is higher than mounts used here explaining the statistically equal results. Shirai et al. ${ }^{[17]}$ also produced PLA/TPS blends by calendering-extrusion and observed lower density values $\left(0.96\right.$ to $1.19{\mathrm{~g} . \mathrm{cm}^{-3}}^{-3}$. They used a proportion between PLA and TPS of 1:3.33 while at the present study a proportion of about 2.5:1 was used, which could explain the difference.

During the calendering-extrusion process, sheets thickness is controlled by the rolls speed, the distance between them and the stretching capacity of the formulation. According to Table 2, the thickness values obtained for all the sheets was closer ( 316 to $391 \mu \mathrm{m})$, suggesting that gelatin addition did not interfere in the processability of the PLA/TPS blends.

\subsection{Sheets morphology}

The blend morphology was assessed by SEM observation of the sheets' surface and fracture. In the micrographs presented in Figure 2 it is possible to observe that sheets fractures presented different characteristics. The control formulation (Figure 2, FC-A) presented a porous structure while the formulation with $1 \mathrm{wt} \%$ of gelatin showed fibrous characteristic that provides hollows in the structure.

Table 2. Density and thickness values of the extruded PLA/TPS/ gelatin sheets.

\begin{tabular}{ccc}
\hline Formulation & Density $\left(\mathbf{g . c m}^{-3}\right)$ & Thickness $(\boldsymbol{\mu m})$ \\
\hline FC & $1.25 \pm 0.09$ & $357 \pm 47$ \\
FG1 & $1.31 \pm 0.09$ & $316 \pm 25$ \\
FG3 & $1.22 \pm 0.07$ & $391 \pm 40$ \\
FG5 & $1.04 \pm 0.10$ & $320 \pm 79$ \\
\hline
\end{tabular}

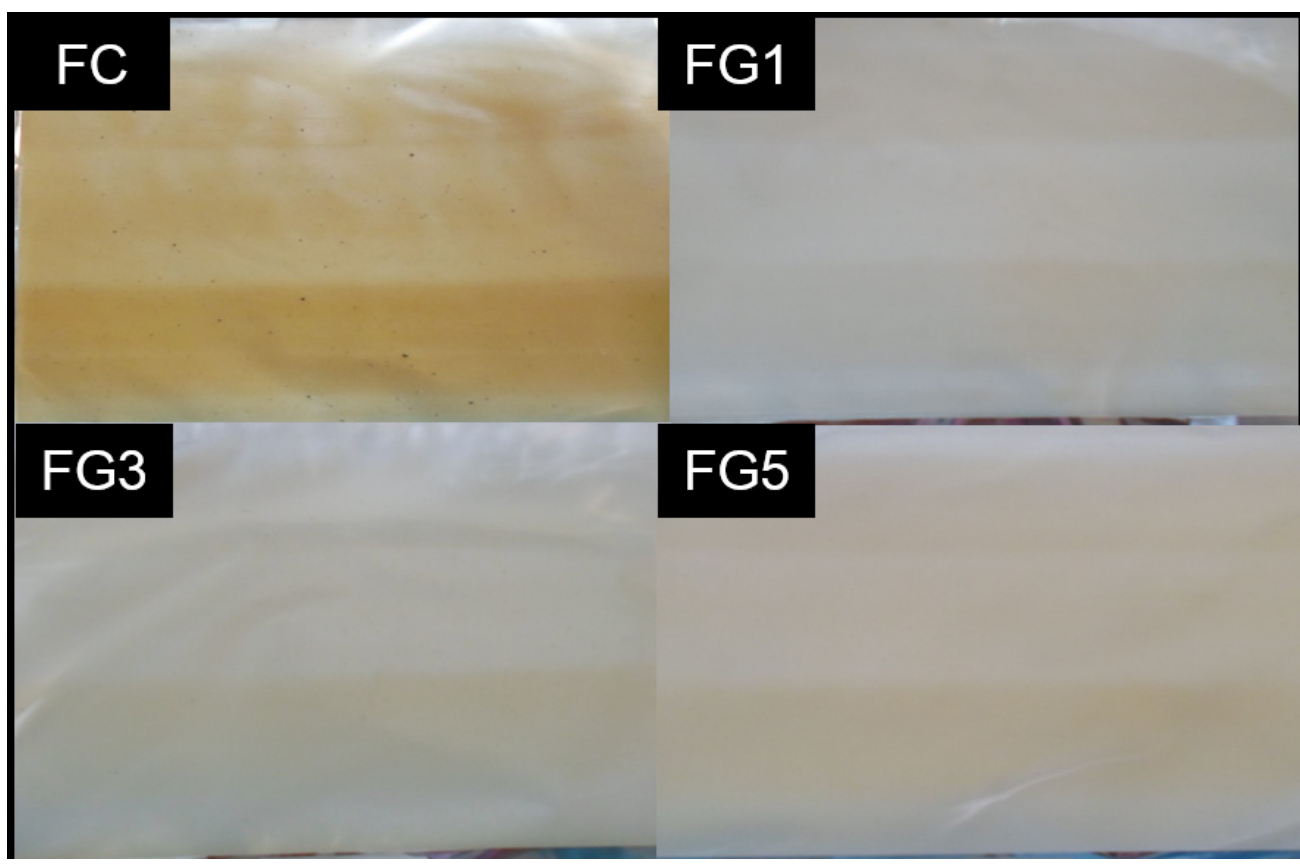

Figure 1. Sheets photographic images FC (control sample), FG1 (0.5\% gelatin), FG3 (1.5\% gelatin) and FG5 (2.5\% gelatin). 
The formulations FG3 and FG5 presented structures with low porosity and higher solidity.

At the surface of all formulations, it is possible to observe that non-gelatinized starch granules are present. Between the formulations with gelatin, FG1 was the one that presented a more irregular surface. Similar results were obtained by Zhang et al. ${ }^{[22]}$ that observed protrusions at the surface of gelatin/starch films, and that the density of the irregularities increased directly with the starch proportion. The authors suggest that the two phases present different shrinking rates during the drying period. In the case of the present study, it
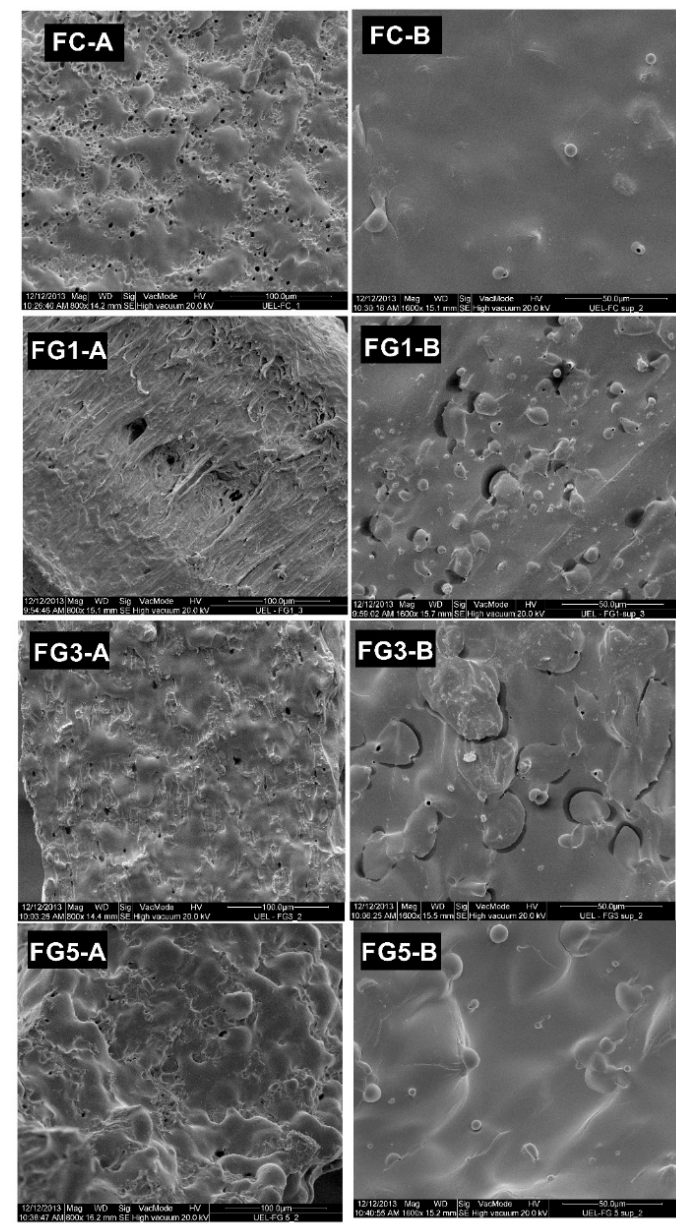

Figure 2. Sheets micrographs where (A) fracture (magnification: $800 \mathrm{x}$ ) and (B) surface (magnification: 1,600 x): FC (control sample), FG1 (0.5\% gelatin), FG3 (1.5\% gelatin) and FG5 (2.5\% gelatin). is probable that the conformation rate of the polymers was different during the cooling step after lamination.

Guzman-Sielicka et al. ${ }^{[16]}$ produced PLLA, gelatin and TPS blends containing calcium carbonate by thermopressing. They observed an increase in the surface porosity when the amount of gelatin was increased in the formulations. This effect was undetectable in the images of Figure 2 probably due to the smallest proportions of gelatin used (up to $5 \mathrm{wt} \%$ in relationship to the total formulation) while the authors used from 10 to $40 \mathrm{wt} \%$.

\subsection{Water vapor permeability (WVP), moisture content and water solubility}

The water vapor permeability (WVP), moisture content and water solubility results are shown in Table 3. Permeability can be defined as the product of diffusivity and solubility when Fick and Henry laws fully apply. For most edible films the water vapor strongly interacts with polymer structure, which results in diffusion and solubility coefficients dependent on driving force ${ }^{[23-25]}$. The addition of gelatin increased significantly the WVP of the sheets, conferring more hydrophilicity to the materials. The tightly bonds (hydrogen bonds and hydrophobic interactions) present in gelatin structure and the polar groups of amino acids resulted in brittle materials in dry state with high moisture absorption, as described by Karnnet et al. ${ }^{[26]}$. Gelatin is composed of repeated sequences of amino acids such as glycine, proline and hydroxyproline. These sequences are responsible for the triple helical structure of gelatin and its ability to form gels and immobilize water molecules. It is possible that gelatin have a greater water retention capacity than starch, explaining the higher values of WVP of gelatin added sheets ${ }^{[27]}$.

Al-Hassan and Norziah ${ }^{[28]}$ obtained WVP results ranging from 4 to $5 \times 10^{-6} \mathrm{~g} \cdot \mathrm{m}^{-1} \cdot \mathrm{Pa}^{-1}$.day ${ }^{-1}$ for sorgo and gelatin films (glycerol was used as plasticizer). Fakhouri et al. ${ }^{[1]}$ reported WVP values of $3.38 \mathrm{~g} \cdot \mathrm{m}^{-1} \cdot \mathrm{Pa}^{-1}$.day ${ }^{-1}$ for lipophilic corn starch and gelatin films plasticized with caprilic acid. Jamshidian et al. ${ }^{[29]}$ characterized pure PLLA films produced by casting related lower WVP values $\left(2.7 \times 10^{-15} \mathrm{~kg} \cdot \mathrm{mm}^{-2}\right.$.s ${ }^{1} . \mathrm{Pa}^{1}$ ) than the ones obtained in this study, under relative humidity gradient of $0-90 \%$. Soares et al. ${ }^{[14]}$ obtained WVP values ranging from 21.6 to $43.68 \times 10^{-6} \mathrm{~g} \cdot \mathrm{m}^{-1} \cdot \mathrm{Pa}^{-1}$. day $^{-1}$ in TPS/PLA (70/30) films produced by extrusion and thermopressing. Similar results of WVP were reported by Shirai et al. ${ }^{[17]}$ in PLA/TPS (70/30) sheets plasticized with adipate and citrate esters, under the same gradient humidity.

The results of moisture content (Table 3 ) of the sheets did not show significant difference $(p>0.05)$. However, it is possible to note that as the amount of gelatin in the

Table 3. Water vapor permeability (WVP), moisture content and water solubility values of PLA/ TPS / gelatin sheets: FC (control sample), FG1 (0.5\% gelatin), FG3 (1.5\% gelatin) and FG5 (2.5\% gelatin).

\begin{tabular}{|c|c|c|c|}
\hline Formulation & WVP $\left(g^{\prime} \cdot m^{-1} \cdot P^{-1} \cdot\right.$ day $\left.^{-1}\right)\left(x 1^{6}\right)$ & Moisture (\%) & Water Solubility (\%) \\
\hline $\mathrm{FC}$ & $2.83^{\mathrm{a}} \pm 0.07$ & $4.51 \pm 0.32$ & $8.67^{\mathrm{a}} \pm 0.34$ \\
\hline FG1 & $3.25^{\mathrm{a}} \pm 0.003$ & $4.39 \pm 1.78$ & $11.44^{b} \pm 0.65$ \\
\hline FG3 & $3.45^{\mathrm{a}} \pm 0.07$ & $5.73 \pm 0.28$ & $20.34^{c} \pm 2.09$ \\
\hline FG5 & $10.10^{\mathrm{b}} \pm 1.14$ & $5.44 \pm 0.18$ & $27.72^{\mathrm{d}} \pm 2.79$ \\
\hline
\end{tabular}

Means followed by the same letters in the column did not show differences at $5 \%$ of significance level according Tukey test. 
formulation increased there was a significant increase in solubility $(p<0.05)$. This result is probably due to the increased solubility of gelatin in water since plasticized gelatin films are completely soluble ${ }^{[30]}$.

Water solubility of the control and FG5 $(2.5 \%$ gelatin) sheets ranged from 8.67 to $27.72 \%$, respectively. The dissolution of hydrophilic polymers is accounted to the penetration of water in the polymer bulk and subsequent swelling, followed by disruption of hydrogen and Van der Walls forces between polymer chains ${ }^{[31]}$. Water absorption and matrix solubilization of hydrophilic polymers was already investigated and the proposed mechanism takes into account the mechanical relaxation of the polymer chains as well as kinetic and thermodynamic factors ${ }^{[32]}$. Authors demonstrated that the predominant factor is kinetic in nature (water diffusion) although the thermodynamic factor and the physical state of water (liquid or vapor) may led to higher liquid water permeability than vapor water permeability. It is worth noting that polymer conformation was found to play an important role in water-matrix interactions in the case of water-sensitive films. The addition of a plasticizer (PEG400) to methylcellulose films was found to increase the dissolution rate in water due to the disruption of methylcellulose microstructure cause by the presence of PEG400 ${ }^{[33]}$. A similar effect could explain the fact that water solubility increased more than 3 times with only $2.5 \%$ gelatin (FC5). Since starch and gelatin were both gelatinized in the extrusion processs, the new interactions formed during molecules rearrangement probably presented lower energy than those of the original materials.

Evaluating the solubility of gelatin and corn starch films plasticized with caprilic acid, Fakhouri et al. ${ }^{[11]}$ observed values up to $44.82 \%$. Soares et al. ${ }^{[14]}$ determined the solubility of the sheets produced with PLA/TPS as equal to $35.2 \%$. The higher solubility found by these authors in comparison with the present study was due to the difference between the proportion of PLA and TPS employed to produce the sheets, which was 30:70 (PLA/TPS). In the present research, the proportion of PLA/(TPS + gelatin) was 50:50. Due their hydrophobic character, PLA is not soluble in water and the higher concentration promoted solubility with different values.

\subsection{Moisture sorption isotherms}

The moisture sorption isotherms of the PLA/TPS and PLA/TPS/gelatin sheets are presented in Figure 3 and the GAB model parameters are listed in Table 4. It is worth noting that the information derived from isotherms is helpful to determine the required water barrier properties of the packaging material necessary for the protection of a particular system. Furthermore, the sorption isotherm provides information about the hydrophilicity of TPS based materials. In the first part of the sorption curve $\left(a_{w}<0.30\right)$, the amount of water adsorbed was similar for all the sheets. This first part corresponds to water field adsorbed as a monolayer, where polar groups of high binding energy to hydrophilic components (starch and proteins) are saturated with water molecules which are considered integral parts of the solid phase ${ }^{[25]}$.

An increase in the moisture content was observed between aw from 0.3 to 0.9 mainly to PLA/TPS sheets with gelatin addition. According to other authors ${ }^{[34,35]}$, the accumulation of water occurs at the polymeric matrix surface as well as at intermolecular free spaces resulting in partial swelling, which in turn may expose additional hydrophilic binding sites. It is possible that the gelatin addition to the sheets' formulation promoted a higher exposure of binding sites increasing the interaction with water molecules. In this stage, it could be considered that water can bind either to starch primary or secondary hydroxyls in association with glycerol or gelatin in association with glycerol, or bind it directly to the free glycerol.

The GAB model fairly represented the experimental data with correlation coefficient of 0.99 , and similar behavior was observed in PLA/TPS sheets with addition of adipate and citrate esters and produced by calendaring-extrusion ${ }^{[17]}$, TPS/PLA films produced by extrusion and thermopressing ${ }^{[36,37]}$, and thermoplastic wheat flour and PLA blends ${ }^{[34]}$.

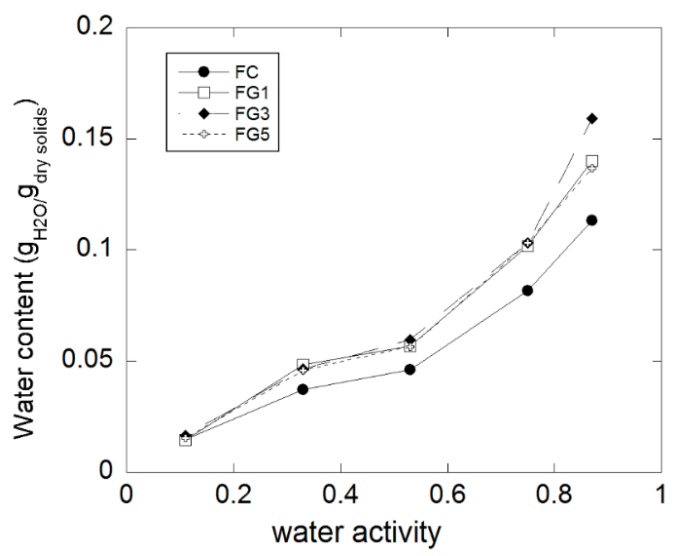

Figure 3. Moisture sorption isotherm for the PLA / TPS / gelatin sheets: FC (control sample), FG1 (0.5\%gelatin), FG3 (1.5\% gelatin) and FG5 ( $2.5 \%$ gelatin)

Table 4. GAB model parameters for moisture sorption isotherms for PLA/ TPS / gelatin sheets: FC (control sample), FG1 (0.5\% gelatin), FG3 (1.5\% gelatin) and FG5 (2.5\% gelatin).

\begin{tabular}{|c|c|c|c|c|}
\hline \multirow{2}{*}{ Formulation } & \multicolumn{4}{|c|}{ GAB parameters } \\
\hline & $m_{0}$ (g water/g dry solids) & $\mathbf{K}$ & $\mathbf{C}$ & $\mathbf{R}^{2}$ \\
\hline $\mathrm{FC}$ & 0.031 & 0.84 & 8.65 & 0.99 \\
\hline FG1 & 0.042 & 0.83 & 6.59 & 0.99 \\
\hline FG3 & 0.036 & 0.89 & 8.86 & 0.99 \\
\hline FG5 & 0.044 & 0.81 & 5.73 & 0.99 \\
\hline
\end{tabular}

$\mathrm{m}_{\mathrm{o}}=$ monolayer water content; $\mathrm{K}=$ sorption heat of the multilayer; $\mathrm{C}=$ Guggenheim constant; $\mathrm{R}^{2}=$ correlation coefficient. 
Table 5. Mechanical properties of PLA/TPS/gelatin extruded sheets: FC (control sample), FG1 (0.5\% gelatin), FG3 (1.5\% gelatin) and FG5 (2.5\% gelatin).

\begin{tabular}{cccr}
\hline Formulation & Tensile strenght (MPa) & Elongation at rupture (\%) & Young's modulus (MPa) \\
\hline FC & $28.8^{\mathrm{a}} \pm 2.1$ & $31.7^{\mathrm{a}} \pm 6.1$ & $614^{\mathrm{a}} \pm 51$ \\
FG1 & $19.4^{\mathrm{c}} \pm 1.5$ & $37.2^{\mathrm{a}} \pm 8.9$ & $469^{\mathrm{c}} \pm 27$ \\
FG3 & $22.7^{\mathrm{b}} \pm 0.9$ & $36.0^{\mathrm{a}} \pm 9.7$ & $520^{\mathrm{b}} \pm 39$ \\
FG5 & $19.8^{\mathrm{c}} \pm 0.8$ & $20.5^{\mathrm{b}} \pm 3.1$ & $483^{\mathrm{b}, \mathrm{c}} \pm 25$ \\
\hline
\end{tabular}

Means followed by the same letters in the column did not show differences at $5 \%$ of significance level according Tukey test.

The monolayer moisture content $\left(\mathrm{m}_{\mathrm{o}}\right)$ indicates the maximum amount of water that can be adsorbed in a single layer per gram of dry film and it is a measure of number sorbing sites ${ }^{[38]}$. In general, it is associated with the material hygroscopicity and hydrofilicity. The inclusion of gelatin increased $\mathrm{m}_{\mathrm{o}}$ values, indicating greater water sorption capacity corroborating with WVP, moisture and solubility results discussed before. The $m_{0}$ values were lower than those reported by Abdillahi et al. ${ }^{[34]}$ for wheat flour and PLA blends ( 0.05 to $0.09 \mathrm{~g}$ water/g dry solids), and by Soares et al. ${ }^{[37]}$ for TPS/PLA sheets ( 0.047 to $0.056 \mathrm{~g}$ water/ $\mathrm{g}$ dry solids). The difference was mainly due to the higher concentration of hydrophilic materials (starch and wheat flour) that was used to produce the materials.

" $\mathrm{K}$ " parameter is related to the sorption heat of the multilayer, and when $\mathrm{K}=1$, it is assumed that there is no interaction of the water vapor in the multilayer or no variation in the energy of sorption in multilayer, which occur in homogeneous solids ${ }^{[39]}$. In our study, this parameter was not affected by gelatin addition. Finally, the parameter " $\mathrm{C}$ " is associated with the sorption heat of the monolayer, and no clear correlation between the samples was observed. Despite the fact that the "C" values are consistent with values found in other studies that worked with starch based materials $^{[17,40]}$.

\subsection{Mechanical properties}

The results associated with mechanical properties such as tensile strength, Young's modulus and elongation at break are presented in Table 5. The gradual addition of gelatin in PLA/TPS sheets significantly affected the mechanical properties $(p<0.05)$. A decrease of about $30 \%$ was observed in tensile strength, Young's modulus and elongation at break when $5 \%$ of gelatin was added, which can be explained by the incompatibility between the blend's components. The mechanical properties of the sheets are directly linked to interfacial adhesion between the blend polymers. When the polymers are mixed, it is interesting that the dispersion and the distribution of the particles occur, forming a single polymeric phase. Poor dispersal could result in the formation of clusters from the entanglement of the polymer chains, which reduces the transmission of tension $^{[37]}$. In the SEM images observed before, the presence voids and non-gelatinized starch granules complicate the load transfer under stress, explaining the results.

Films made from blends of cassava starch and gelatin by casting technique presented increased tensile strength as gelatin was added, due to their reinforcement properties to the polymeric matrix ${ }^{[10,12]}$. In our study similar results were not observed, because of the presence of hydrophobic polymer like PLLA and their incompatibility between starch and gelatin, as described in other studies ${ }^{[15,41]}$. Although starch and gelatin are hydrophilic and compatible, they are immiscible and presented as two phases ${ }^{[13]}$.

Several reports describe the production of PLLA/gelatin blend and TPS/gelatin blends by casting methods ${ }^{[10,12,13]}$. The main problem with films produced through this technique is the limitation on the quantity produced, and the use of solvents to disperse components. Although the gelatin addition affected the sheets' mechanical properties, it was possible to produce them by extrusion and calendering process at pilot scale, which could be an alternative to offer biodegradable packaging for low moisture foods in commercial scale.

\section{Conclusions}

PLA/TPS/gelatin sheets were successfully produced by calendaring-extrusion process at pilot scale. The inclusion of gelatin in PLA/TPS blends interfered significantly in the microstructural, mechanical and water barrier properties, while density and the water vapor permeability were unaffected. The PLA/TPS/gelatin sheets obtained have the potential to become biodegradable packaging for food.

\section{Acknowledgements}

The authors would like to thank Coordenação de Aperfeiçoamento de Pessoal de Nível Superior (CAPES) and Fundação Araucária for their financial support and to Laboratório de Microscopia Eletrônica da Universidade Estadual de Londrina (UEL) for the SEM images.

\section{References}

1. Bordes, P., Pollet, E., \& Averous, L. (2009). Nano-biocomposites: biodegradable polyester/nanoclay systems. Progress in Polymer Science, 34(2), 125-155. http://dx.doi.org/10.1016/j. progpolymsci.2008.10.002.

2. Fortunati, E., Latterini, L., Rinaldi, S., Kenny, J. M., \& Armentano, I. (2011). PLGA/Ag nanocomposites: in vitro degradation study and silver ion release. Journal of Materials Science. Materials in Medicine, 22(12), 2735-2744. PMid:22002470. http://dx.doi.org/10.1007/s10856-011-4450-0.

3. Liao, H.-T., \& Wu, C.-S. (2009). Preparation and characterization of ternary blends composed of polylactide, poly( $\varepsilon$-caprolactone) and starch. Materials Science and Engineering A, 515(1-2), 207-214. http://dx.doi.org/10.1016/j.msea.2009.03.003.

4. Lescher, P., Jayaraman, K., \& Bhattacharyya, D. (2012). Characterization of water-free thermoplastic starch blends for 
manufacturing processes. Materials Science and Engineering A, 532(1), 178-189. http://dx.doi.org/10.1016/j.msea.2011.10.079.

5. Luckachan, G. E., \& Pillai, C. K. S. (2011). Biodegradable polymers: a review on recent trends and emerging perspectives. Journal of Polymers and the Environment, 19(3), 637-676. http://dx.doi.org/10.1007/s10924-011-0317-1.

6. Genkina, N. K., Kozlov, S. S., Martirosyan, V. V., \& Kiseleva, V. I. (2014). Thermal behavior of maize starches with different amylose / amylopectin ratio studied by DSC analysis. Starch, 66(7-8), 1-7. http://dx.doi.org/10.1002/star.201300220.

7. Taghizadeh, A., Sarazin, P., \& Favis, B. D. (2013). High molecular weight plasticizers in thermoplastic starch/polyethylene blends. Journal of Materials Science, 48(4), 1799-1811. http://dx.doi. org/10.1007/s10853-012-6943-8.

8. Cavallaro, G., La Manna, G., Liveri, V. T., Aliotta, F., \& Fontanella, M. E. (1995). Structural investigation of water/ lecithin/cyclohexane microemulsions by FT-IR spectroscopy. Journal of Colloid and Interface Science, 176(2), 281-285. http://dx.doi.org/10.1006/jcis.1995.9966.

9. Veiga-Santos, P., Oliveira, L. M., Cereda, M. P., \& Scamparini, R. P. (2007). Sucrose and inverted sugar as plasticizer: effect on cassava starch-gelatin film mechanical properties, hydrophilicity and water activity. Food Chemistry, 103(2), 255-262. http:// dx.doi.org/10.1016/j.foodchem.2006.07.048.

10. Fakhouri, F. M., Costa, D., Yamashita, F., Martelli, S. M., Jesus, R. C., Alganer, K., Collares-Queiroz, F. P., \& Innocentini-Mei, L. H. (2013). Comparative study of processing methods for starch/gelatin films. Carbohydrate Polymers, 95(2), 681-689. PMid:23648030. http://dx.doi.org/10.1016/j.carbpol.2013.03.027.

11. Fakhouri, F. M., Fontes, L. C. B., Innocentini-Mei, L. H., \& Collares-Queiroz, F. P. (2009). Effect of fatty acid addition on the properties of biopolymer films based on lipophilic maize starch and gelatin. Stärke, 61(9), 528-536. http://dx.doi. org/10.1002/star.200800217.

12. Fakhouri, F. M., Maria Martelli, S., Canhadas Bertan, L., Yamashita, F., Innocentini-Mei, L. H., \& Collares-Queiroz, F. P. (2012). Edible films made from blends of manioc starch and gelatin: influence of different types of plasticizer and different levels of macromolecules on their properties. LWT - Food Science and Technology, 49(1), 149-154. http://dx.doi. org/10.1016/j.1wt.2012.04.017.

13. Liu, X., Wang, Y., Zhang, N., Shanks, R. A., Liu, H., Tong, Z., Chen, L., \& Yu, L. (2014). Morphology and phase composition of gelatin-starch blends. Chinese Journal of Polymer Science, 32(1), 108-114. http://dx.doi.org/10.1007/s10118-014-1377-1.

14. Soares, F. C., Yamashita, F., Müller, C. M. O., \& Pires, A. T. N. (2013). Thermoplastic starch/poly(lactic acid) sheets coated with cross-linked chitosan. Polymer Testing, 32(1), 94-98. http://dx.doi.org/10.1016/j.polymertesting.2012.09.005.

15. Shirai, M. A., Grossmann, M. V. E., Mali, S., Yamashita, F., Garcia, P. S., \& Müller, C. M. O. (2013). Development of biodegradable flexible films of starch and poly (lactic acid) plasticized with adipate or citrate esters. Carbohydrate Polymers, 92(1), 19-22. PMid:23218260. http://dx.doi.org/10.1016/j. carbpol.2012.09.038.

16. Guzman-Sielicka, A., Janik, H., \& Sielicki, P. (2013). Proposal of new starch-blends composition quickly degradable in marine environment. Journal of Polymers and the Environment, 21(3), 802-806. http://dx.doi.org/10.1007/s10924-012-0558-7.

17. Shirai, M. A., Müller, C. M. O., Grossmann, M. V. E., \& Yamashita, F. (2015). Adipate and citrate esters as plasticizers for poly(lactic acid)/thermoplastic starch sheets. Journal of Polymers and the Environment, 23(1), 54-61. http://dx.doi. org/10.1007/s10924-014-0680-9.

18. Müller, C. M. O., Laurindo, J. B., \& Yamashita, F. (2011). Effect of nanoclay incorporation method on mechanical and water vapor barrier properties of starch-based films. Industrial Crops and Products, 33(3), 605-610. http://dx.doi.org/10.1016/j. indcrop.2010.12.021.

19. American Society for Testing and Material - ASTM. (1996). E96-00: standard test methods for water vapor transmission of materials. West Conshohocken: ASTM.

20. American Society for Testing and Material - ASTM. (2002). D882-02: standard test methods for tensile properties of thin plastic sheeting. West Conshohocken: ASTM.

21. Choi, Y. S., Hong, S. R., Lee, Y. M., Song, K. W., Park, M. H., \& Nam, Y. S. (1999). Study on gelatin-containing artificial skin: I. Preparation and characteristics of novel gelatin-alginate sponge. Biomaterials, 20(5), 409-417. PMid:10204983. http:// dx.doi.org/10.1016/S0142-9612(98)00180-X.

22. Zhang, N., Liu, X., Yu, L., Shanks, R., Petinaks, E., \& Liu, H. (2013). Phase composition and interface of starch-gelatin blends studied by synchrotron FTIR micro-spectroscopy. Carbohydrate Polymers, 95(2), 649-653. PMid:23648025. http://dx.doi.org/10.1016/j.carbpol.2013.03.045.

23. Bonilla, J., Atarés, L., Vargas, M., \& Chiralt, A. (2013). Properties of wheat starch film-forming dispersions and films as affected by chitosan addition. Journal of Food Engineering, 114(3), 303-312. http://dx.doi.org/10.1016/j.jfoodeng.2012.08.005.

24. Chambi, H., \& Grosso, C. (2006). Edible films produced with gelatin and casein cross-linked with transglutaminase. Food Research International, 39(4), 458-466. http://dx.doi. org/10.1016/j.foodres.2005.09.009.

25. Bertuzzi, M. A., Vidaurre, E. C., Armada, M., \& Gottifredi, J. C. (2007). Water vapor permeability of edible starch based films. Journal of Food Engineering, 80(3), 972-978. http:// dx.doi.org/10.1016/j.jfoodeng.2006.07.016.

26. Karnnet, S., Potiyaraj, P., \& Pimpan, V. (2005). Preparation and properties of biodegradable stearic acid-modified gelatin films. Polymer Degradation \& Stability, 90(1), 106-110. http:// dx.doi.org/10.1016/j.polymdegradstab.2005.02.016.

27. Fiszman, S. M., Lluch, M. A., \& Salvador, A. (1999). Effect of addition of gelatin on microstructure of acidic milk gels and yoghurt and on their rheological properties. International Dairy Journal, 9(12), 895-901. http://dx.doi.org/10.1016/ S0958-6946(00)00013-3.

28. Al-Hassan, A. A., \& Norziah, M. H. (2012). Starch-gelatin edible films: Water vapor permeability and mechanical properties as affected by plasticizers. Food Hydrocolloids, 26(1), 108-117. http://dx.doi.org/10.1016/j.foodhyd.2011.04.015.

29. Jamshidian, M., Tehrany, E. A., Imran, M., Akhtar, M. J., Cleymand, F., \& Desobry, S. (2012). Structural, mechanical and barrier properties of active PLA-antioxidant films. Journal of Food Engineering, 110(3), 380-389. http://dx.doi.org/10.1016/j. jfoodeng.2011.12.034.

30. Pereda, M., Ponce, A. G., Marcovich, R., Ruseckaite, A., \& Martucci, J. F. (2011). Chitosan-gelatin composites and bi-layer films with potential antimicrobial activity. Food Hydrocolloids, 25(5), 1372-1381. http://dx.doi.org/10.1016/j. foodhyd.2011.01.001.

31. Turhan, K. N., \& Şahbaz, F. (2004). Water vapor permeability, tensile properties and solubility of methylcellulose-based edible films. Journal of Food Engineering, 61(3), 459-466. http://dx.doi.org/10.1016/S0260-8774(03)00155-9.

32. Morillon, V., Debeaufort, F., Capelle, M., Blond, G., \& Voilley, A. (2000). Influence of the physical state of water on the barrier properties of hydrophilic and hydrophobic films. Journal of Agricultural and Food Chemistry, 48(1), 11-16. PMid:10637042. http://dx.doi.org/10.1021/jf990809z.

33. Turhan, K. N., \& Şahbaz, F. (2004). Water vapor permeability, tensile properties and solubility of methylcellulose-based 
edible films. Journal of Food Engineering, 61(3), 459-466. http://dx.doi.org/10.1016/S0260-8774(03)00155-9.

34. Abdillahi, H., Chabrat, E., Rouilly, A., \& Rigal, L. (2013). Influence of citric acid on thermoplastic wheat flour/poly(lactic acid) blends. II. Barrier properties and water vapor sorption isotherms. Industrial Crops and Products, 50(1), 104-111. http://dx.doi.org/10.1016/j.indcrop.2013.06.028.

35. Godbillot, L., Dole, P., Joly, C., Roge, B., \& Mathlouthi, M. (2006). Analysis of water binding in starch plasticized films. Food Chemistry, 96(3), 380-386. http://dx.doi.org/10.1016/j. foodchem.2005.02.054.

36. Müller, M. O. C., Pires, A. T. N., \& Yamashita, F. (2012). Characterization of thermoplastic starch/poly(lactic acid) blends obtained by extrusion and thermopressing. Journal of the Brazilian Chemical Society, 23(3), 426-434. http://dx.doi. org/10.1590/S0103-50532012000300008.

37. Soares, F. C., Yamashita, F., Müller, C. M. O., \& Pires, A. T. N. (2014). Effect of cooling and coating on thermoplastic starch/ poly(lactic acid) blend sheets. Polymer Testing, 33(1), 34-39. http://dx.doi.org/10.1016/j.polymertesting.2013.11.001.

38. Mali, S., Sakanaka, L. S., Yamashita, F., \& Grossmann, M. V. E. (2005). Water sorption and mechanical properties of cassava starch films and their relation to plasticizing effect. Carbohydrate Polymers, 60(3), 283-289. http://dx.doi. org/10.1016/j.carbpol.2005.01.003.

39. Brandelero, H., Grossmann, M. V., Yamashita, F. (2013). Hidrofilicidade de filmes de amido/poli(butileno adipato-cotereftalato) (pbat) adicionados de tween 80 e óleo de soja. Polímeros: Ciência e Tecnologia, 23(2), 270-275. http://dx.doi. org/10.1590/S0104-14282013005000011.

40. Müller, C. M. O., Laurindo, J. B., \& Yamashita, F. (2012). Composites of thermoplastic starch and nanoclays produced by extrusion and thermopressing. Carbohydrate Polymers, 89(2), 504-510. PMid:24750751. http://dx.doi.org/10.1016/j. carbpol.2012.03.035.

41. Zhao, X., Liu, W., \& Yao, K. (2006). Preparation and characterization of biocompatible poly (L-lactic acid)/ gelatin blend membrane. Journal of Applied Polymer Science, 101(1), 269-276. http://dx.doi.org/10.1002/app.23292.

Received: May 19, 2015

Revised: Mar. 17, 2016

Accepted: Apr. 28, 2016 